проф. д-р пед. н. Наталья Николаевна Нижнева

Белорусский государственный университет, Минск

Филологический факультет

тел. +37529697749

e-mail: nizhneva_nn@mail.ru

д-р фил. н. Надежда Леонидовна Нижнева-Ксенофонтова

Белорусский государственный университет, Минск

Филологический факультет

тел. +375173341274

e-mail:nksena@rambler.ru

канд. фил. н. Владислав Анатольевич Ксенофонтов

Белорусский государственный университет, Минск

Филологический факультет

тел. +375173341274

e-mail: nksena@rambler.ru

\title{
МЕТОДОЛОГИЧЕСКИЕ АСПЕКТЫ АРГУМЕНТАЦИИ И ИХ ПРИМЕНЕНИЕ В ПЕДАГОГИЧЕСКОЙ ДЕЯТЕЛЬНОСТИ
}

\section{STRESZCZENIE}

Metodologiczne aspekty argumentacji i ich zastosowanie w działalności dydaktycznej

W artykule rozpatrywane są aspekty metodologiczne argumentacji w kontekście działalności dydaktycznej. Omówiona jest geneza teorii argumentacji i jej konceptualne miejsce w warunkach obecnych. Uwypuklono treść głównych sposobów argumentacji, podstaw organizacji dyskusji, zasad efektywnej komunikacji, których wykorzystanie będzie sprzyjać powodzeniu działalności dydaktycznej. 
Słowa kluczowe: działalność dydaktyczna, metodologiczne aspekty argumentacji, sposoby argumentacji, dyskusja, argumentacja.

\section{SUMMARY}

\section{Methodological aspects of argumentation and their application in pedagogical activities}

Methodological aspects of argumentation in the context of pedagogical activities are analyzed in the article. Genesis of argumentation theory and its conceptual propositions under presentday conditions are presented. Content of the main means of argumentation, rules of discussion organization, principles of effective communication that can provide successful pedagogical activities are revealed.

Key words: pedagogical activities, methodological aspects of argumentation, means of argumentation, discussion, communication.

Важнейшим условием успешности педагогической деятельности является умение выбора аргументов для воздействия на аудиторию, а также их научно обоснованного использования в процессе убеждения обучающихся. Без овладения теоретическими и практическими основами теории аргументации сложно говорить о достижении целей педагогического воздействия в целом.

Значительное большинство людей с тем или иным успехом убеждают других, не всегда обращаясь за помощью к методологическим основам аргументации. Часть людей считают, что умение убеждать является вполне естественным процессом. Безусловно, это заблуждение. Рассмотрим генезис и современные аспекты развития теории аргументации, определим основные пути достижения целей в педагогической деятельности с учетом ее развития.

Теория аргументации зарождается в период античности, эпоху перехода от мифа к логосу. В то время человек, не удовлетворенный объяснением мира в форме мифа все активнее обращается к разуму. Идет формирование науки логики, исследующей законы и операции правильного мышления, «а вместе с нею и теории аргументации - дисциплины, изучающей технику убеждения» ${ }^{1}$.

1 А.А. Ивин, Теория и практика аргументаиии: учебник для бакалавров, Москва 2013, s. 14. 
Стоит отметить, что интерес к теории аргументации предполагает определенную социальную среду. Он возникает в обществе, в котором существует потребность убеждения посредством речи, а не посредством принуждения, насилия и т.д. Развитие теории аргументации предполагает формирование демократического жизнеустройства, в котором слово выступает основным средством воздействия на умы и души людей.

Теория аргументации достигла расцвета в Древней Греции, но уже в Древнем Риме, как только демократия начала постепенно свертываться, теория аргументации приходит в упадок.

Первыми учителями красноречия в Древней Греции были Тисий и Кораскс, которые ввели в обиход понятие плана ораторской речи и осуществили схематизацию содержания речи. Постепенно формировался целый комплекс приемов убеждения аудитории. Сократ сравнивал эти приемы с приемами борьбы. Теория аргументации как обучение способам победить противника в состязании за доверие слушателей рассматривалась как искусство интеллектуальной борьбы.

Значительных успехов в исследовании искусства убеждения и в обучении ему добились философы-софисты, которые первыми стали брать плату за обучение.

Софисты осмыслили речь как искусство, подчиняющееся определенным приемам и правилам, они подчеркнули, что она далеко не всегда копирует реальность, но допускает ложь и обман. Протагор настаивал на том, что «человек есть мера всех вещей», и что как кому кажется, так оно и есть на самом деле, он уверял, что может заставить слушателя в корне изменить свои убеждения по любому вопросу. Горгий, в свою очередь, выдвинул идею условности человеческого знания, мнения, из чего следует, что с помощью слов можно менять представления слушателя в соответствии с целями оратора. Софисты не стремились выяснить в споре истину, они ставили целью выдать слабое за сильное, а сильное - за слабое, не заботясь о том, как все обстоит на самом деле.

Острую полемику с софистами развернул Сократ, который считал, что настоящего искусства речи «нельзя достичь без познания истины, да и никогда это не станет возможным».

Платон в отличие от софистов полагал, что в содержании речи главное постигнуть суть предмета, определить, к какому роду относится то, о чем оратор собирается говорить.

Возникновение теории аргументации можно связывать с написанием Аристотелем книги «Риторика». Он определил теорию аргументации как «способность находить возможные приемы убеждения относительно каждого предмета». Другими словами, эта наука должна исследовать уни- 
версальные, не зависящие от обсуждаемых объектов способы, или приемы убеждения.

Аристотель выделил три фактора, определяющих убедительность речи:

- характер самой речи;

- особенности говорящего;

- особенности слушающих.

Он ведет разговор преимущественно о внешних факторах убеждения, и почти не рассматривал внутренние, связанные с самой речью. А как раз исследование внутренних факторов должно быть определяющим в теории аргументации.

Античность настаивала на исключительном значении для убеждения логического доказательства, кроме того происходило пренебрежение опытом, эмпирическим подтверждением выдвигаемых идей. Эти две особенности привели риторику к многовековому застою.

Со времен Цицерона теория аргументации как наука остановилась в своем развитии. Из искусства убеждающей речи теория аргументации все больше превращалась в искусство красноречия.

В Средние века убедительность речи «определяется количеством приведенных в ней логически правильных доказательств и используемыми в ней словесными украшениями» ${ }^{2}$.

Возрождение теории аргументации началось в середине XX века. Она восстановила то позитивное, что было в «античной риторике», «стала уделять особое внимание эмпирическому обоснованию, а также обоснованию путем ссылки на традицию, здравый смысл, интуицию, веру, вкус и т.П.» ${ }^{3}$.

В настоящее время теория аргументации лишена единой парадигмы. Ее история напоминает историю логики. До середины XX века ее основное содержание мало чем отличалось от того, что было сделано в период античности.

В классическом своем смысле выражение «теория аргументации» означает теорию способов убеждения. Ее внимание сосредоточено на содержании убеждений, а не на том эмоциональном фоне, на котором они возникают и существуют.

Наш повседневный язык выполняет многие задачи. Мы не только передаем определенную информацию, но и выражаем свои чувства, воздействуя на тех, к кому обращена наша речь.

2 Там же, s. 19.

3 Там же. 
Убеждение не является чистой информацией. Оно столь же насыщено, как и сама человеческая жизнь, и окружающая нас действительность.

В формировании убеждения используются все возможности языка.

Теория аргументации должна учитывать все три составляющие ситуации речевого убеждения:

- речь, призванную внушить определенные убеждения;

- говорящего, или оратора;

- аудиторию, к которой обращена речь ${ }^{4}$.

Факторы, которые влияют на убедительность речи можно разделить на внутренние, связанные с содержанием речи, и внешние, касающиеся говорящего (оратора) и аудитории. Внутренние факторы называются также способами аргументации или убеждения. Они являются основными в процессе убеждения. Научная аргументация использует главным образом внутренние, а не внешние факторы.

Внешним факторам убеждения посвящена обширная научная и популярная литература. Можно выделить хорошо известные работы Д. Карнеги, посвященные психологическим аспектам взаимоотношений оратора и аудитории.

Ключевой своей задачей теория аргументации ставит задачу изучения способов убеждения, оставляя на периферии другие менее важные вопросы, связанные с убеждением.

Способы аргументации остаются пока недостаточно исследованными. В частности, известный российский специалист профессор А.А. Ивин предлагает использовать в качестве общего основания классификации характер аудитории, на которую способно распространяться воздействие аргументации. Исходя из данного основания все способы аргументации можно разделить на универсальные и неуниверсальные, или контекстуальные ${ }^{5}$.

Универсальная аргументация применима в любой аудитории. К универсальным способам убеждения относятся прямое эмпирическое подтверждение (в частности подтверждение следствий), многообразные способы теоретической аргументации: логическое обоснование, системная аргументация, методологическая аргументация и др.

Неуниверсальная, или контекстуальная, аргументация эффективна лишь в определенной аудитории. Данные способы убеждения охватывают аргументы к традиции и авторитету, к интуиции и вере, к здравому смыслу и вкусу и др.

4 Там же, s. 27.

5 Там же, s. 29. 
Граница между универсальной и контекстуальной аргументацией относительна.

Универсальную аргументацию иногда характеризуют как «рациональную», а «контекстуальную» - как «нерациональную». Такое различение не является оправданным. Как отмечает профессор А.А. Ивин, «оно резко сужает сферу «рационального», исключая из нее большую часть гуманитарных и практических рассуждений» ${ }^{6}$. Контекстуальная аргументация должна быть принята как необходимая составная часть рациональной аргументации. Стоит учитывать, что особенности мышления человека и его возможности определяются эпохой.

Как отмечалось, все многообразные способы универсальной аргументации можно разделить на эмпирические и теоретические.

Неотъемлемым элементом эмпирической аргументации является ссылка на опыт, на эмпирические данные.

Теоретическая аргументация опирается на рассуждения и не пользуется непосредственно ссылками на опыт.

Различие между эмпирической и теоретической аргументацией относительно.

Ядро приемов эмпирической аргументации составляют способы эмпирического обоснования знания, называемые также (эмпирическим) подтверждением, или верификацией.

Подтверждение может быть прямым, или непосредственным, и косвенным.

Прямое подтверждение - это непосредственное наблюдение тех явлений, о которых говорится в обосновываемом утверждении ${ }^{7}$ Наиболее универсальным способом подтверждения в опыте является косвенное подтверждение - выведение из обосновываемого положения логических следствий и их последующая опытная проверка ${ }^{8}$. При этом подтверждение следствий оценивается как свидетельство в пользу истинности самого положения.

Если ограничить круг способов обоснования утверждений их прямым или косвенным подтверждением в опыте, то окажется непонятным, каким образом все-таки удается переходить от гипотез к теориям, от предположений к истинному знанию. Эмпирическое обоснование должно быть дополнено теоретическим обоснованием. Опыт при всей его важности и незаменимости не дает абсолютной гарантии истинности полученного знания.

\footnotetext{
6 Там же, s. 30.

7 Там же, s. 33.

8 Там же, s. 37.
} 
Из разных способов теоретической аргументации важное значение имеют: логическая аргументация (выведение обосновываемого утверждения из других, ранее принятых утверждений), системная аргументация (обоснование утверждения путем включения его в хорошо проверенную систему утверждений, или теорию), принципиальная проверяемость и принципиальная опровержимость (демонстрация принципиальной возможности эмпирического подтверждения и эмпирического опровержения обосновываемого утверждения), условие совместимости (показ того, что обосновываемое положение находится в хорошем согласии с законами, принципами и теориями, относящимися к исследуемой области явлений), методологическая аргументация (обоснование утверждения путем ссылки на тот надежный метод, с помощью которого оно получено) ${ }^{9}$.

Одним из важных способов теоретической аргументации является логическое доказательство.

Доказательство - это выведение обосновываемого положения из иных, ранее принятых положений. В доказательстве различают тезис - утверждение, которое надо доказать, и основание, или аргументы, - те утверждения, с помощью которых обосновывается тезис. Понятие доказательства всегда предполагает указание посылок, на которые опирается тезис, и тех логических правил, по которым осуществляются преобразования утверждений в ходе доказательства ${ }^{10}$. Никакие приемы и красноречие неспособны помочь, если нет хорошо обоснованных идей и убедительных доказательств.

Доказательство представляет собой определенного рода умозаключение или цепочку умозаключений. Все, что в логике говорится об умозаключениях имеет прямое отношение к доказательству. Доказательства применимы во всех областях рассуждений и в любой аудитории.

Важным способом теоретического обоснования является системная аргументация, под которой понимается - соответствие вновь выдвигаемого положения уже принятым утверждениям, согласие его с некоторыми общими принципами, подобными принципу привычности, методологическая аргументация ${ }^{11}$. Общие утверждения, научные законы, принципы и т.п. не могут быть обоснованы чисто эмпирически, путем ссылки только на опыт. Они требуют также теоретического обоснования, опирающегося на рассуждение и отсылающего к другим принятым утверждениям. Без этого нет ни абстрактного теоретического знания, ни хорошо обоснованных убеждений. Системная аргументация - обоснование утверждения путем

9 Там же, s. 32.

10 Там же, s. 62.

11 Там же, s. 85. 
включения его в качестве составного элемента в кажущуюся хорошо обоснованную систему утверждений, или теорию ${ }^{12}$. Утверждение, ставшее элементом теории, опирается уже не только на отдельные факты, но во многом также на широкий круг явлений, объясняемых теорией, на предсказание ею новых, ранее неизвестных эффектов, на связи ее с другими теориями. Анализируемое положение, включенное в теорию, получает ту эмпирическую и теоретическую поддержку, какой обладает теория в целом.

От обосновываемого утверждения требуется, чтобы оно находилось в согласии с фактическим материалом, на базе которого и для объяснения которого оно выдвинуто. Должно выполняться условие совместимости обосновываемое утверждение должно соответствовать имеющимся в рассматриваемой области законам, принципам, теориям.

Как известно, метод - это система предписаний, рекомендаций, предостережений, образцов и т.п., указывающих, как сделать что-то. В свою очередь, методологическая аргументация - это обоснование отдельного утверждения или целостной концепции путем ссылки на тот надежный метод, с помощью которого получены обосновываемое утверждение или отстаиваемая концепция ${ }^{13}$.

Универсальные способы убеждения, подобные обращению к опыту и логическому обоснованию, применимы в любой аудитории. Наряду с универсальной аргументацией широко используется также неуниверсальная (контекстуальная, ситуативная) аргументация, эффективная не в любой, а лишь в некоторых аудиториях.

Исторический характер человеческого существования предполагает, что свои основные жизненные проблемы человек решает, опираясь не столько на универсальные, сколько на контекстуальные, зависящие от времени и от среды доводы. На контекстуальной аргументации держатся в конечном счете мораль, религия, право и другие социальные институты. Из всех контекстуальных аргументов наиболее употребим и значим аргумент к традиции.

Традиция представляет собой анонимную, стихийно сложившуюся систему образцов, норм, правил и т.п., которой руководствуется в своем поведении достаточно обширная и устойчивая группа людей ${ }^{14}$. Традиция может быть настолько широкой, что охватывает все общество в определенный период его развития. Наша повседневная жизнь во многом опирается

\footnotetext{
12 Там же, s. 86.

13 Там же, s. 101.

14 Там же, s. 117.
} 
на традицию, и обращение к ней - стандартный прием практической аргументации.

Аргумент к авторитету - это ссылка на мнение или действия лица, прекрасно зарекомендовавшего себя в данной области своими суждениями или поступками ${ }^{15}$. Конечно, ссылка на авторитет, на сказанное или написанное кем-то не относится к универсальным способам обоснования. Возможности человека ограничены, он не может все проанализировать и проверить. Он вынужден полагаться на мнения и суждения других. Стоит помнить, что из напечатанного и сказанного ранее можно встретить и небылицы, поэтому нет оснований воспринимать напечатанное некритично.

Может использоваться и интуитивная аргументация как ссылка на непосредственную, интуитивную очевидность выдвигаемых положений. Известно, что интуиция - прямое усмотрение истины, постижение ее без всякого рассуждения и доказательства ${ }^{16}$. В чистом виде интуитивная аргументация является редкостью.

Интуиции близка вера - глубокое, искреннее, эмоционально насыщенное убеждение в справедливости какого-то положения или концепции. Вера заставляет принимать положения за достоверные и доказанные без критики и обсуждения. Как и интуиция, вера субъективна.

Здравый смысл играет особую роль в гуманитарной аргументации и при обсуждении проблем, касающихся жизнедеятельности человека. Здравый смысл примерным образом характеризуется как общее, присущее каждому человеку чувство истины и справедливости, приобретаемое с жизненным опытом. Здравый смысл в основе своей не является знанием. Это способ отбора, благодаря которому в знании различаются главное и второстепенное и обрисовываются крайности. Аргумент к здравому смыслу - это обращение с целью поддержки выдвигаемого положения к чувству здравого смысла, несомненно имеющемуся у аудитории ${ }^{17}$.

Аргументация к вкусу - это обращение к чувству вкуса, имеющемуся у аудитории и способному склонить ее к принятию выдвинутого положения. Вкус касается только совершенства каких-то вещей и опирается на непосредственное чувство, а не на рассуждение ${ }^{18}$.

Аргументация - разновидность человеческой деятельности и руководствуется определенными правилами и принципами. Она может быть корректной и некорректной. Корректной она будет, если не нарушаются

15 Там же, s. 124.

16 Там же, s. 133.

17 Там же, s. 148.

18 Там же, s. 151. 
определенные требования к ней в сложившейся области, и наоборот, если не соблюдены процедуры обоснования, нарушен процесс коммуникации и т.п. Нормы, распространяющиеся на аргументацию как сферу человеческой деятельности разнородны и многочисленны. В силу этого граница между корректной и некорректной очень условна и меняется от одной области аргументации к другой. Прием аргументации корректный в пропаганде может быть некорректным в научной аргументации.

Некоторые некорректные приемы аргументации, которые часто используются и получили имена ${ }^{19}$.

Аргумент к аудитории - попытка опереться на мнения, чувства и настроения аудитории вместо обоснования тезиса объективными доводами. В этом случае человек обращается не к партнеру по спору, а к другим участникам и стремится привлечь их на свою сторону, апеллируя к их чувствам, а не к разуму.

Аргумент к личности - приписывание оппоненту недостатков, реальных или мнимых, представляющих его в смешном свете, бросающих тень на его умственные способности, подрывающих доверие к его рассуждениям. Как правило, сущность спора уходит на второй план, а предметом обсуждения становится личность оппонента.

Аргумент к массам - попытка взволновать широкий круг людей, используя их групповой эгоизм, национальные или расовые предрассудки, давая лживые обещания т.п. Этот аргумент часто называют демагогией.

Аргумент к человеку - использование в поддержку своей позиции оснований, выдвигаемых противной стороной в споре или вытекающих из принимаемых ею положений.

Аргумент к тщеславию - расточение неумеренных похвал противнику в споре в надежде, что тронутый комплиментами он станет покладистей.

Аргумент к несмелости или к авторитету - обращение в поддержку своих взглядов к идеям и именам тех людей, с кем оппонент не посмеет спорить.

Аргумент к силе - угроза неприятными последствиями, в частности угроза применения насилия или прямое употребление каких-то средств принуждения.

Аргумент к незнанию или невежеству - ссылка на неосведомленность, а то и невежество оппонента в вопросах, относящихся к существу спора.

Аргумент к жалости - возбуждение в другой стороне жалости и сочувствия.

19 Там же, s. 195-198. 
Все перечисленные аргументы являются некорректными способами защиты своей позиции.

В аргументации недопустимы и такие уловки, как умышленный уход от темы, длинные рассуждения о вещах, не имеющих отношения к обсуждаемым вопросам, попытки запутать основную мысль в различных подробностях, чтобы незаметно переключить внимание аудитории на выигрышные моменты и т.п. Указанные разновидности некорректных аргументов не исчерпывают всей области некорректной аргументации. Отнесение конкретного аргумента к корректным или некорректным во многих случаях зависит от ситуации, в которой он используется.

Способы универсальной (эмпирической и теоретической) и контекстуальной аргументации составляют основу всех способов аргументации, но ими не исчерпывается множество возможных приемов убеждения.

Аргументация является неотъемлемой частью дискуссии.

В свою очередь, организация дискуссии в процессе проведения занятий является эффективным средством активизации познавательной деятельности обучающихся.

Как отмечает профессор М.А. Кремень, «дискуссия - это коллективное исследование проблемы, в которой каждая сторона, оппонируя, опровергая мнение собеседника (противника), аргументирует (отстаивает) свою позицию (концепцию) и претендует на достижение цели (истины)» ${ }^{20}$. Это определение подходит к понятиям: беседа, диалог, прения, дебаты, спор и полемика. Если участники дискуссии не владеют культурой ее проведения, то они сбиваются с истинного пути и переходят на эмоциональный уровень.

Выясним основные принципы организации дискуссии. Их знание способствует правильному взаимодействию сторон.

Первый принцип: содействие возникновению альтернативы. Основанием этого принципа является метод анализа. Данный принцип обязывает ведущего способствовать плюрализму мнений. Без альтернативы нет противоположности, а следовательно развития дискуссии и разрешения противоречия. Пренебрежение им ведет к монополии на пути решения той или иной проблемы.

Второй принцип: конструктивная критика. Он обязывает нас проверять на прочность любую альтернативу, разрушать стереотипы и не допускать распространения ложных мнений. Конструктивной критика является

20 М.А. Кремень, Практическая психология управления: пособие для студентов вузов, Минск 2011, s. 281. 
тогда, когда обосновывается «почему нет». Без нее наука и общественная практика приходит к застою.

Третий принцип: обеспечение социальной защищенности личности. Принцип предполагает гарантии обеспечения права людям на защиту в случае преследования за критику ${ }^{21}$.

Процесс поиска истины в мыслительной деятельности проходит фазы дискуссии:

1. Информирование. Это вступительное слово ведущего, задача которого четко обозначить проблему, чтобы завязать дискуссию.

2. Аргументация. На данном этапе докладчики аргументировано обосновывают альтернативы и стремятся к достижению своих целей. Задача ведущего следить за научной достоверностью выводов и исчерпывающим доказательством истины.

3. Замечания. Данная фаза включает вопросы, сомнения и возражения оппонентам, докладчикам и выступающим.

4. Опровержение. Это предполагает ослабление ошибочного мнения, недопущение его распространения.

5. Критика. Фазы опровержения и критики часто совпадают. Необходимо знать приемы конструктивной критики, уметь парировать аргументацию другой стороны.

6. Контраргументация. Защита альтернативы после критического анализа. «Контр» означает противодействие, исключающее предложенную альтернативу. Управляя дискуссией, ведущему следует добиваться, чтобы критика носила конструктивный характер. Это важное условие качественного продвижения в процессе познания.

7. Выработка решения. На данном этапе ведущему необходимо сделать обобщение, оценить степень достижения истины. У участников дискуссии на этом этапе складывается представление, кто ближе к истине. Важно отметить положительные и отрицательные моменты в аргументации сторон.

8. Завершение. Конец обсуждения проблемы предполагает принятие решения. Когда у участников не вырабатывается единое мнение, то ведущий берет на себя ответственность поставить точку в споре, определить чья позиция отличается более сильной аргументацией, имеет научную и практическую ценность ${ }^{22}$.

21 Там же, s. 282-283.

22 Там же, s. 283-284. 
Дискуссия ведется с различными целями.

Стратегические цели: обмен мнениями, выработка приемлемого решения для всех сторон, согласие по проблеме, поиск выхода из сложного положения, анализ ситуации, поиск истины, получение дополнительного знания, отбор конструктивных предложений, пополнение банка идей.

Тактические цели: могут быть конструктивными и спекулятивными. Конструктивные цели: систематизация знаний о предмете, сплочение сторонников, расширение круга единомышленников и привлечение заинтересованных, оценка путей дальнейшего развития, выработка позиции коллектива, выявление общественного мнения, опровержение ненаучных знаний, защита конструктивной идеи, формирование устойчивого интереса к проблеме, привлечение сторонников к активному сотрудничеству. Спекулятивные цели непримиримых противников: создание препятствий и заведение проблемы в тупик, истощение интеллектуальных сил соперников, дискредитация инакомыслящих, нейтрализация сопротивляющихся, публичное осмеяние оступившихся, введение в заблуждение аудитории, усугубление разногласий и т.д. ${ }^{23}$

Именно методологические аспекты аргументации, рассмотренные выше в процессе осуществления дискуссии играют важнейшую роль. Пособие по дисциплине Теория аргументации, по мнению А.А. Ивина, является наукой о способах убеждения, о тех многообразных приемах воздействия на аудиторию, которые позволяют изменять убеждения последней.

Важной разновидностью аргументации являются переговоры. Это общение переговаривающихся сторон. Задача каждой из сторон убедить другую сторону в своей правоте и приемлемости предлагаемых ею решений. Переговоры являются своего рода искусством, которое дается не каждому, но которому можно в определенной мере научиться. Стоит овладеть основными требованиями к процессу переговоров. Целесообразно начинать с самых простых, которые касаются принципов эффективной коммуникации людей.

Первое правило: в процессе общения, и в частности в ходе убеждения, соблюдайте так называемый «принцип вежливости» или «принцип взаимной вежливости». Принцип вежливости предполагает выполнение следующих требований: максима такта, максима великодушия, максима одобрения, максима скромности, максима согласия, максима симпатии. Принцип вежливости опирается, в первую очередь, на насчитывающую многие тысячелетия практику успешной коммуникации.

23 Там же, s. 285. 
Второе правило: искренне интересуйтесь другими людьми. Если вы хотите, чтобы люди испытывали радость от общения с вами, вы сами должны испытывать радость, соприкасаясь с ними.

Третье правило: будьте хорошим слушателем, при этом поощряйтесвоих собеседников говорить о самих себе. Полезно дать собеседнику высказаться с начала и до конца, даже если его рассуждения временами кажутся вам неинтересными.

Четвертое правило: старайтесь говорить о том, что интересует вашего собеседника. Самый верный путь к сердцу человека - это беседа с ним о том, что он ценит превыше всего.

Пятое правило: внушайте вашему собеседнику сознание его значительности, причем делайте это искренне. Человек ищет одобрения со стороны тех, с кем он общается, точно также, как каждый из нас желает признания окружающими наших подлинных достоинств.

Шестое правило: проявляйте уважение к мнению своего собеседника, избегайте говорить человеку, что он неправ. Если человек ошибается, можно дать понять ему, что он не прав, взглядом, интонацией или жестом.

Седьмое правило: драматизируйте свои идеи, подавайте их эффектно. Просто констатировать истину или правильное решение во многих случаях стало уже недостаточным.

Восьмое правило: старайтесь задавать собеседнику вопросы, вместо того чтобы ему приказывать. Вряд ли кто-нибудь любит, когда ему прямолинейно приказывают.

Девятое правило: демонстрируйте открытость, почаще улыбайтесь и, если это вам удается, шутите. Открытость - одно из несомненных преимуществ человека, вступающего в процесс коммуникации.

Десятое правило: следует помнить, что имя человека - это один из самых приятных и самых важных для него звуков. Обычного человека больше интересует его собственное имя, чем любые другие имена в мире ${ }^{24}$.

Только практическое применение вышеизложенных правил позволяет превратить абстрактную теорию аргументации в практическое искусство убеждения.

Убедить, а тем более переубедить кого-либо - сложная задача. Для ее решения необходимо соблюдать следующие принципы:

1. Принцип формулировки конкретной цели выступления. Цель убеждающей презентации - сформулировать или изменить мнение слушателей.

24 А.П. Панфилова, Имидж делового человека: учебное пособие, Санкт-Петербург 2007, s. 229$-236$. 
2. Принцип адаптации к установкам слушателей. Установка - это позитивные или негативные устойчивые чувства, связанные с человеком, объектом или вопросом.

3. Принцип хороших доводов или доказательств. Убедить аудиторию легче, когда выступающий на презентации владеет разумными доводами и доказательствами в поддержку своих целей. Довод - это заявление, объясняющее, почему предложение оправдано.

4. Принцип организации доводов в соответствии с установками аудитории. Отбирая доводы, необходимо прогнозировать реакцию слушателей.

Таким образом, знание и использование преподавателями теоретических и практических аспектов аргументации, знание правил организации дискуссии, принципов эффективной коммуникации со слушателями будет способствовать оптимизации образовательного процесса, активизации познавательной деятельности обучающихся, а также наиболее эффективному формированию у них профессиональных компетенций, и соответственно, успешной педагогической деятельности.

\section{Литература}

Белова А.Д., Лингвистические основы аргументаиии, Киев 2003.

Ивин А.А., Теория и практика аргументащии: учебник для бакалавров, Москва 2013.

Кремень М.А., Практическая психология управления: пособие для студентов вузов, Минск 2011.

Леонтьев А.А., Психология общения: учеб. пособие, Москва 2008.

Москвин А.А., Аргументативная риторика: теоретический курс для филологов, Ростов-на-Дону 2008.

Нижнева Н.Н., Искусство речи, Минск 2000.

Нижнева Н.Н., Риторика. Культура мьциления, Минск 2002.

Нижнева-Ксенофонтова Н., Культура речи. Практические занятия. Методические рекомендации, Минск 2005.

Панасюк А.Ю., Как убеждать в своей правоте: Современнье психотехнологии убеждающего воздействия, Москва 2002.

Панфилова А.П., Имидж делового человека: учебное пособие, Санкт-Петербург 2007.

Старченко А., Бовао Ш., К вопросу о научном статусе теории аргументации, „Вестник Московского университета. Серия 7. Философия" 1985, № 5.

Стернин И.А., Основы речевого воздействия: учеб. издание, Воронеж 2012.

Blair J.A., Tindale's Acts of arguing: A rhetorical model of argument, „Informal Logic” 2000, Vol. 20 (2).

Nizhneva N.N., Zaniewski J., Stylistic gambit, „Edukacja dla przyszłości” 2012, t. 9. 
Nizhneva Natallia, Zaniewski Jan, Nizhneva-Ksenafontava Nadzeya, Linguistic gambit: an introduction to the study of language, Bialystok 2012.

Tindale C.W., Rhetorical Argumentation: Principles of Theory and Practice, SAGE Publications 2004 . 